\title{
A method for study of the conditioned pinna response in the albino rabbit',
}

R. E. LUBOW AND R. MARKMAN ${ }^{3}$

NORTH CAROLINA STATE UNIVERSITY

\begin{abstract}
A technique was developed for conditioning the pinna reflex in the albino rabbit. The harness, animal preparation, method of sensing and recording pinna movement, and testing procedure were described.
\end{abstract}

\section{Introduction}

The New Zealand rabbit has proved to be well adapted for use as a subject in classical conditioning studies. In addition to the usual desirable laboratory traits such as ease of maintenance and genetic uniformity, it is a superbly docile animal. Neither an elaborate harness nor a long period of adaptation to the harness is necessary for conditioning. In this matter it closely resembles the sheep and goat (Lubow, 1964, 1965) rather than the cat (Weis, 1964); and in ease of conditionability (Gormezano et al, 1962; Schneiderman et al, 1962) is quite dissimilar to the rat (Schlossberg, 1934). The purpose of the present paper is to describe a simple inexpensive method for classical conditioning of the pinna response in the rabbit.

\section{Method}

The Harness

The rabbit support was made from $1 / 4$ in metal tubing welded together to form a rectangular frame resting on four legs. The frame was 15 in high, 20 in long and 9 in wide. A heavy duty canvas sling was folded over and pinned to the two long sides. Four holes were cut for the feet. The height of the sling was adjusted so that S's legs were just short of touching the floor. In addition, four fabric straps were used to secure $S$.

One strap went over the shoulder through the sling and behind the front legs. The second strap went over the back through the sling and in front of the hind legs. The third and fourth straps were placed half way between the first two.

\section{Animal Preparation}

All Ss were prepared two days prior to training. Two $1 / 8$ in holes were punched in the temporal distal portion of the ear. The holes were 1 in apart. Care was taken not to pierce any of the major blood vessels of the pinna. This can be accomplished simply by shining a flashlight through the translucent ear. A Zephiran solution was applied to prevent infection.

$\mathrm{Nu}$-way studs were placed into the ear holes and held with washers and nuts. The studs served as points of attachment for the shock electrodes, and movement transducer, and remained in the ear for the duration of the experiment. A thin, rigid, rectangular piece of plastic, $1-1 / 4$ in by $1 / 2$ in, was pre-drilled to fit over the two ear holes. It was placed between the ear

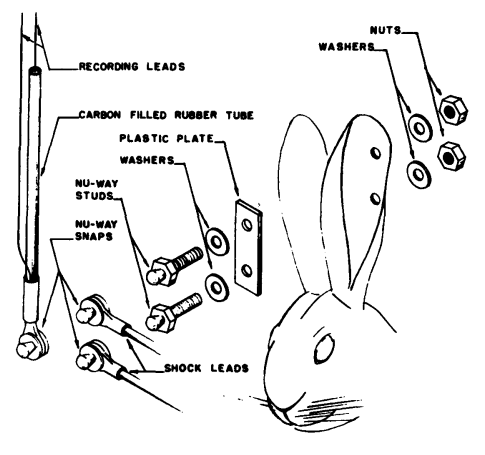

Fig. 1. Exploded view of shock electrodes and motion transducer assembly.

and the washers in order to prevent tearing of the ear holes. Figure 1 shows the configuration discussed. Sensing and recording the movement of the pinna

A catheter tube 7 in long, $1 / 32$ in wall thickness, and $1 / 8$ in inside diameter was filled with powdered carbon. The carbon was obtained from a drycell flashlight battery. A wire lead was inserted into each end of the tube to a depth of about 1 in. One inserted lead was held in place, and the tube sealed, with epoxy. The lead from the top end of the tube was inserted through a rigid hollow tube. The bottom of the rigid tube was epoxied to the top of the carbon tube. Rods and clamps were used to support the rigid tube and carbon tube directly over the ear, and also to adjust the tension of the carbon tube so that its electrical resistance was constant between Ss and for the same $S$ over days.

The circuit was an unbalanced impedance matching circuit. The graphite tube and a resistor of approximately the same value were connected in series. Both were connected in parallel with a 10 volt dry cell battery. A high impedance recorder was connected to the negative end of the battery and to the junction of the fixed resistor and the graphite tube.

The resistance of the carbon tube, at rest, was 20,000 ohms. When supporting the ear the tension on the tube was adjusted to a value of $50,000 \mathrm{ohms}$. A deflection of the ear caused the resistance to vary from $50,000 \mathrm{ohms}$ to 150,000 ohms. A typical unconditioned response resulted in a peak resistance value of $100,000 \mathrm{ohms}$, and a typical conditioned response resulted in a peak resistance value of $75,000 \mathrm{ohms}$.

Recording was done with a,Stoelting No. 345 amplifier and galvanometer recorder. A sample record is shown in Fig. 2. It should be noted that the CR and UR are quite 
dissimilar in amplitude and shape. Direct visual observation of the two responses indicated that the UR was a sharp movement or series of twitches of the ear often accompanied by a shaking of the head. The total UR pattern is easily observable. On the other hand, the CR was not readily observable and apparently consisted of a slight increase in tonus of all bodily members. Test Procedure

The Ss were 10 male New Zealand Rabbits between 60 and 90 days old. Two Ss were run concurrently in adjoining sound attenuated compartments. The Ss were prepared in the manner described. On the first day of acquisition training, $\mathrm{S}$ was placed in the sling and the shock electrodes and movement transducer attached. The $\mathrm{S}$ was adapted to the sling for $15 \mathrm{~min}$. before training. For acquisition training the CS was a $2.5 \mathrm{KC}$ tone, $72 \mathrm{db}$ at $2 \mathrm{ft}$. The tone was produced by a Sonalert Model SC-628 28 VDC signal source (Electropac, Inc. Peterborough, N. Ho). The CS duration was $600 \mathrm{~ms}$. The US was a $100 \mathrm{~ms}$ shock to the ear (Hunter Model 35). The shock intensity was such as to elicita sharp twitch of the ear, and in general corresponded to the number 8 setting on the stimulator, $70 \mathrm{v}$ at the source. The US was presented immediately after the cessation of the CS. The intertrial interval was either 20,30 , or $40 \mathrm{sec}$., randomly selected. Stimulus presentations were programmed on Massey-Dickenson equipment. A pen deflection was counted as a CR when its onset occurred at any time after the CS onset and before the CS offset and whose amplitude was at least a $1 \mathrm{~mm}$ deflection from the baseline.

On day 1 Ss received 40 adaptation trials followed by 80 conditioning trials. Eighty conditioning trials were given on days 2,3 , and 4 . On days 5 and 6,80 extinction trials were administered.

\section{Results and Diseussion}

The adaptation, acquisition, and extinction curves are shown in Fig. 3. These results indicate the success of the conditioning methodology. An analysis of variance for the number of responses as a function of days of acquisition indicates the expected difference between

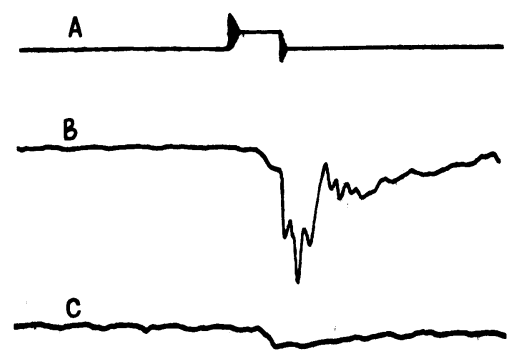

Fig. 2. Sample record: A - conditional stimulus; US onset occurs at trailing edge of CS. B - conditioned response (small deflection), followed by unconditioned response. $C$ - CR during the first extinction trial.

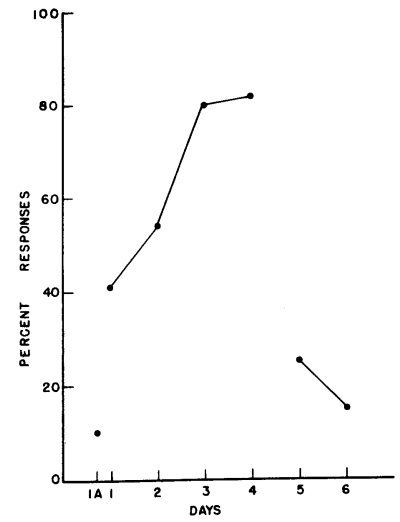

Fig. 3. Percentage responses as a function of days of acquisition and extinction.

days $(F=10.14,3 / 27 \mathrm{df}, \mathrm{p}<.005)$. Likewise an analysis of variance as a function of days for extinction indicates that the decrease as a function of days is significant $(F=5.50 .1 / 9 \mathrm{df}, \mathrm{p}<.05)$. In addition, there is a significant decrease in number of responses to the to-be-conditional stimulus during the 40 adaptation trials as a function of blocks of ten trials $(F=3.41$, $3 / 27 \mathrm{df}, \mathrm{p}<.05)$. It would appear that future studies using the conditioned pinna response of the rabbit must segregate the alpha response by defining its latency so as to differentiate it from true conditioned responses (cf eyelid conditioning, Kimble, 1961, p 55-59).

\section{Referenees}

Brelsford, J. Jr., \& Theios, J. Single session conditioning of the nictitating membrane in the rabbit: Effect of intertrial interval. Psychon. Sci., 1965, 2, 81-82.

Gormezano, I., Schneiderman, N., Deaux, E., \& Fuentes, I. Nictitating membrane: Classical conditioning and extinction in the albino rabbit. Science, 1962, 138, 33-34.

Kimble, G. A. Hilgard and Marquis' conditioning and learning. New York: Appleton-Century-Crofts, 1961.

Lubow, R. E. An integrated response and reinforcement unit for classical and operant conditioning of large mammals. J. exp. Anal. Behav., 1964, 7, 423-424.

Lubow, R. E. Latent inhibition: The effect of frequency of preexposure to CS. J. comp. physiol. Psychol. 1965, in press.

Schneiderman, N., Fuentes, I., \& Gormezano, I. Acquisition and extinction of the classically conditioned eyelid response in the albino rabbit. Science, 1962, 136, 650-652.

Schlosberg, H. Conditioned responses in the white rat. J. genet. Psychol., 1934, 45, 303-335.

Weis, Ann B. A restraining device for cats. J. exp. Anal. Behav., 1964, 7, 441-442.

\section{Notes}

1. This research was supported by NIMH Career Development Award K3-MH 7189 and Grant MH 08731 to R. E. Lubow.

2. The authors thank F. Kozoman for his technical assistance.

3. Now at the University of North Carolina, Chapel Hill.

4. The use of a flexible tube containing powdered carbon to measure small movement was first suggested to the author by a similar device used by A. U. Moore at the Cornell Behavior Laboratory many years ago to record respiratory information from goats and sheep. 